Review

\title{
Chemoradiotherapy enhanced the efficacy of radiotherapy in nasopharyngeal carcinoma patients: a network meta-analysis
}

\author{
Jian He ${ }^{1}$, Ping Wu ${ }^{1}$, Yaoyun Tang ${ }^{1}$, Sulai Liu ${ }^{1}$, Chubo Xie ${ }^{1}$, Shi Luo ${ }^{1}$, Junfeng Zeng ${ }^{1}$, \\ Jing $\mathrm{Xu}^{1}$ and Suping Zhao ${ }^{1}$ \\ ${ }^{1}$ Department of Otorhinolaryngology Head \& Neck Surgery, Province Key Laboratory of Otolaryngology Critical Diseases, \\ Xiangya Hospital of Central South University, Changsha, Hunan, China \\ Correspondence to: Ping Wu, email: csuwoodpink@126.com \\ Keywords: nasopharyngeal carcinoma, chemoradiotherapy, overall survival, complete response, network meta-analysis \\ Received: December 07, $2016 \quad$ Accepted: February 20, 2017 \\ Published: March 17, 2017
}

Copyright: He et al. This is an open-access article distributed under the terms of the Creative Commons Attribution License (CC-BY), which permits unrestricted use, distribution, and reproduction in any medium, provided the original author and source are credited.

\section{ABSTRACT}

Object: A Bayesian network meta-analysis (NMA) was conducted to estimate the overall survival (OS) and complete response (CR) performance in nasopharyngeal carcinoma (NPC) patients who have been given the treatment of radiotherapy, concurrent chemoradiotherapy (C), adjuvant chemotherapy (A), neoadjuvant chemotherapy $(\mathrm{N})$, concurrent chemoradiotherapy with adjuvant chemotherapy $(C+A)$, concurrent chemoradiotherapy with neoadjuvant chemotherapy $(C+N)$ and neoadjuvant chemotherapy with adjuvant chemotherapy $(N+A)$.

Methods: Literature search was conducted in electronic databases. Hazard ratios (HRs) accompanied their $\mathbf{9 5} \%$ confidence intervals ( $95 \% \mathrm{CIs}$ ) or $\mathbf{9 5 \%}$ credible intervals ( $95 \%$ CrIs) were applied to measure the relative survival benefit between two comparators. Meanwhile odd ratios (ORs) with their $\mathbf{9 5 \%}$ CIs or CrIs were given to present CR data from individual studies.

Results: Totally 52 qualified studies with 10,081 patients were included in this NMA. In conventional meta-analysis (MA), patients with $\mathrm{N}+\mathrm{C}$ exhibited an average increase of $9 \%$ in the 3-year OS in relation to those with C+A. As for the NMA results, five therapies were associated with a significantly reduced HR when compared with the control group when concerning 5-year OS. C, C+A and N+A also presented a decreased HR compared with A. There was continuity among 1-year, 3-year and 5-year OS status. Cluster analysis suggested that the three chemoradiotherapy appeared to be divided into the most compete group which is located in the upper right corner of the cluster plot.

Conclusion: In view of survival rate and complete response, the NMA results revealed that $\mathrm{C}, \mathrm{C}+\mathrm{A}$ and $\mathrm{C}+\mathrm{N}$ showed excellent efficacy. As a result, these 3 therapies were supposed to be considered as the first-line treatment according to this NMA.

\section{INTRODUCTION}

Nasopharyngeal carcinoma (NPC), derived from the nasopharynx, is an epidemic cancer in Southeast Asian countries, Southeast China and North Africa [1]. NPC patients often were diagnosed at advanced stages and radiotherapy (RT) was used to be the recommended option for these patients [2]. However, only $30 \%-50 \%$ NPC patients with RT were able to survive for 5 years [3]. Meanwhile, chemical compounds like SSRP1 that are able to reduce the proliferation of NPC tumor cells was identified in previous studies [4]. As a result, the combination of chemotherapy and RT was hypothesized to be an effective therapy to improve the survival status of NPC patients. And such result was verified by studies in the current literatures [5].

Three primary chemoradiotherapies was introduced to control locoregionally advanced NPC: concurrent chemoradiotherapy, concurrent chemoradiotherapy plus adjuvant chemotherapy and concurrent chemoradiotherapy plus neoadjuvant chemoradiotherapy. It was revealed that the 3 mentioned methods worked in totally different 
mechanisms and focused on different purposes. For instance, chemoradiotherapy is prepared for the purpose of multiplying the treatment effects and neoadjuvant chemoradiotherapy is able to reduce the size of tumor before the implementation of RT. It was suggested that patients with neoadjuvant chemoradiotherapy exhibited a lower risk of recurrence in comparison to those with the monotherapy of RT [6].

Although some MA was conducted to compare different chemoradiotherapies, most randomized clinical trials (RCTs) can only compare two or three arms of therapies due to resource constraints and ethical issues. As a result, simultaneously comparison to the efficacy of several chemoradiotherapies cannot be achieved by RCTs or conventional meta-analysis. Therefore, the approach of mixed-treatment comparisons or network meta-analysis (NMA) was adopted in this study in order to overcome the above limitations. It was also expected to examine whether combined chemoradiotherapy was able to provide NPC patients with enhanced efficacy from this NMA. For this reason, evidence was synthesized from studies in which adjuvant chemotherapy, concurrent chemoradiotherapy, neoadjuvant chemotherapy or their binary combination

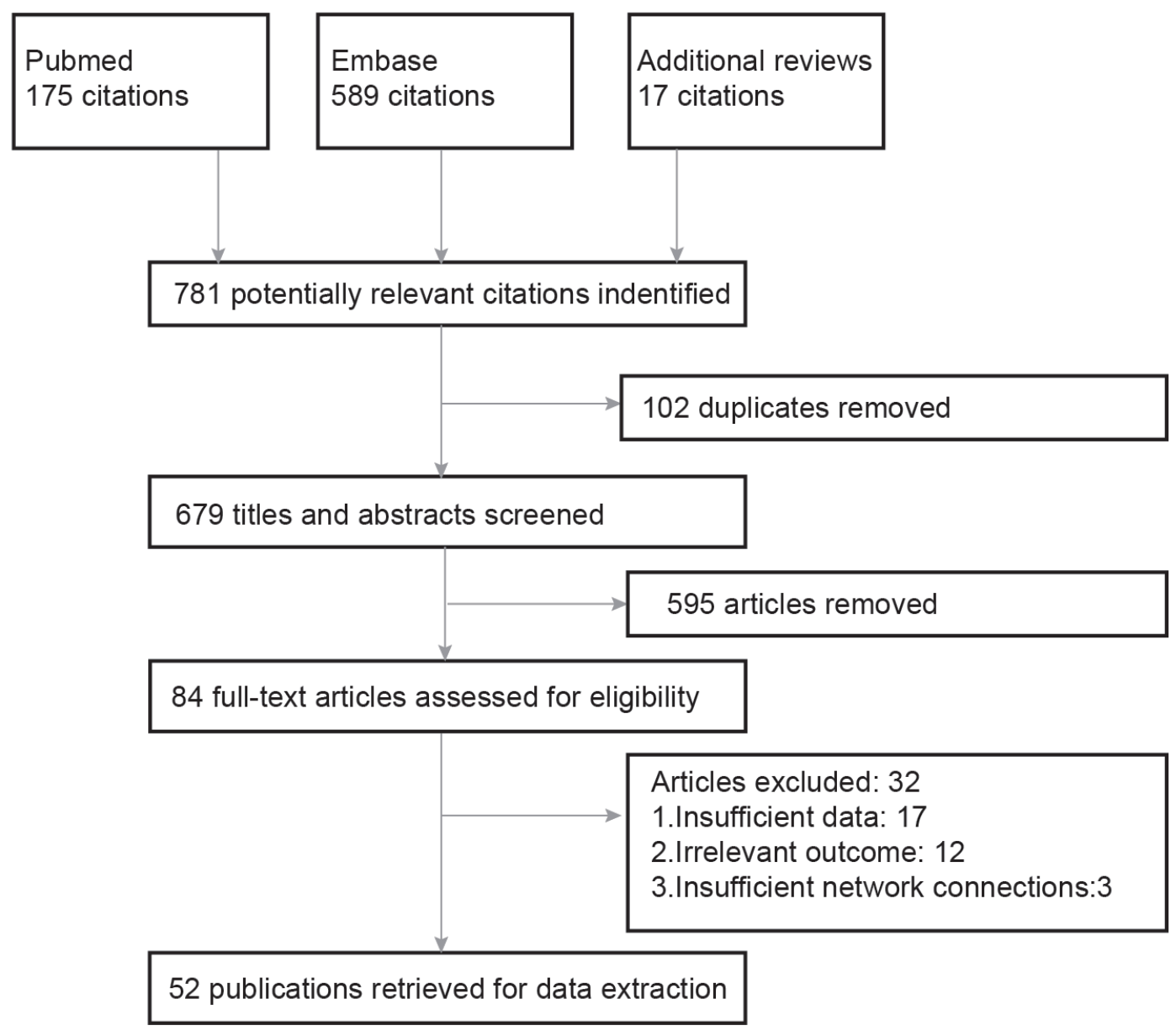

therapies $(\mathrm{A}, \mathrm{C}, \mathrm{N}, \mathrm{A}+\mathrm{C}, \mathrm{N}+\mathrm{C}$ and $\mathrm{A}+\mathrm{N}$ ) were included and compared.. By conducting such a study, genuine consensus can be reached in the current literature which is critical to patients with NPC.

\section{RESULTS}

\section{Baseline characteristics}

As was revealed in the flow chart (Figure 1), a total of 781 articles were identified by two reviewers (PubMed: 175, Embase: 598, additional reviews: 17). Then 595 irrelevant articles as accompanied with 102 duplicates were excluded, resulting in 84 articles for fulltext assessment. After another 32 articles were removed, 52 publications with a total of 10,081 NPC patients were included in the eligibly study list. The baseline characteristics of included studies were shown in Table 1. Besides, the network plots revealing the distribution of trials for each outcome were shown in Figure 2. The size of nodes was proportional to the number of patients with that comparator and the numbers on the edges between

Additional reviews

17 citations

\section{2 duplicates removed}

2.Irrelevant outcome: 12

3.Insufficient network connections:3

Figure 1: Flow chart of study selection. 
Table 1: Characteristics of studies included in the network meta-analysis.

\begin{tabular}{|c|c|c|c|c|c|c|c|c|c|}
\hline \multirow{2}{*}{ Study } & \multirow{2}{*}{ Size } & \multirow{2}{*}{$\begin{array}{l}\text { Follow-up } \\
\text { (month) }\end{array}$} & \multirow{2}{*}{ Disease Stage } & \multirow{2}{*}{ Age } & \multirow{2}{*}{$\begin{array}{r}\text { Male } \\
(\%)\end{array}$} & \multicolumn{2}{|c|}{ Radiotherapy } & \multicolumn{2}{|c|}{ Chemotherapy } \\
\hline & & & & & & Type & Dose/Gy & Intervention 1 & Intervention 2 \\
\hline Al-Sarraf, 1998 & 193 & 30 & AJCC III-IV,WHO I-III & 50 & 67.0 & RT & 70 & $\begin{array}{|lcc|}\begin{array}{l}\text { C cisplatin) }+ \\
\text { (fluorouracil, cisplatin) }\end{array} & \text { A } \\
\end{array}$ & Control \\
\hline Cao, 2015 & 180 & 58.97 & AJCC II-III & 47 & 73.0 & IMRT & 70 & C (cisplatin) & Control \\
\hline Chan, 1995 & 82 & 28.5 & WHO III & 44 & 92.0 & RT & $58-66$ & N (fluorouracil, cisplatin) & Control \\
\hline Chan, 2005 & 350 & 66 & WHO I-III,UICC II-IV & 45 & 80.0 & RT & 66 & C (cisplatin) & Control \\
\hline Chen, 2008 & 316 & 29 & AJCC III-IVb & 46 & 73.4 & RT & 70 & $\begin{array}{|lcc|}\begin{array}{l}\text { C cisplatin) }+ \\
\text { (fluorouracil, cisplatin) }\end{array} & \text { A } \\
\end{array}$ & Control \\
\hline Chen, 2011 & 220 & 60 & AJCC II-III,WHO II-III & 42 & 70.7 & RT & $68-70$ & C (cisplatin) & Control \\
\hline Chen, 2012 & 508 & 37.8 & WHO III-IVb & 44 & 77.0 & RT & 66 & $\begin{array}{lll}\mathrm{C} & \text { (cisplatin) }+ & + \\
\text { (fluorouracil, cisplatin) } & \mathrm{A}\end{array}$ & C (cisplatin) \\
\hline Chi, 2002 & 157 & 49.5 & WHO I-III & 46 & 77.9 & RT & 70.2 & \begin{tabular}{l|}
$\begin{array}{l}\text { A (leucovorin, fluorouracil, } \\
\text { cisplatin) }\end{array}$ \\
\end{tabular} & Control \\
\hline Chua, 1998 & 334 & 30 & AJCC I-IV,M0 & 47 & 75.0 & RT & 71 & $\mathrm{~N}$ (epirubicin, cisplatin) & Control \\
\hline Cvitkovic, 1996 & 339 & 49 & WHO I-III,M0 & 42 & 75.0 & RT & $65-70$ & $\begin{array}{l}\text { N (bleomycin, epirubicin, } \\
\text { cisplatin) }\end{array}$ & Control \\
\hline Ding, 2011 & 56 & 3 & TNM II-IV & 48 & 60.7 & RT & 70 & $\begin{array}{|lcc|}\begin{array}{l}\text { C cisplatin) }+ \\
\text { (fluorouracil, cisplatin) }\end{array} & \text { A } \\
\end{array}$ & C (cisplatin) \\
\hline Fountzilas, 2012 & 141 & 55 & WHO I-III & 49 & 71.0 & RT & 70 & $\begin{array}{l}\mathrm{N} \text { (epirubicin, cisplatin, } \\
\text { paclitaxel) }+\mathrm{C} \text { (cisplatin) }\end{array}$ & C (cisplatin) \\
\hline Ge, 2009 & 52 & - & TNM II-III & 54 & 76.9 & RT & 70 & $\mathrm{C}(\mathrm{CMNa})$ & Control \\
\hline Guan, 2016 & 69 & 35 & AJCC I-IV,WHO II-III & 48 & 85.7 & IMRT & 60 & C (cisplatin) & Control \\
\hline Hareyama, 2002 & 80 & 49 & WHO I-III & 50 & 75.0 & RT & $66-68$ & N (fluorouracil, cisplatin) & Control \\
\hline Huang, 2012 & 200 & - & WHO II-III & 44 & 56.0 & RT & $66-78$ & $\begin{array}{l}\mathrm{N} \text { (fluorouracil, carboplatin) } \\
+\mathrm{C} \text { (carboplatin) }\end{array}$ & C (carboplatin) \\
\hline Huang, 2015 & 408 & 133.3 & UICC II-IV & 45 & 77.6 & RT & $66-78$ & $\begin{array}{l}\mathrm{N} \text { (floxuridine, carboplatin) } \\
+\mathrm{C} \text { (carboplatin) }\end{array}$ & $\begin{array}{l}\mathrm{N} \text { (floxuridine, } \\
\text { carboplatin) }\end{array}$ \\
\hline Hui, 2009 & 65 & - & UICC III-IV & 50 & 61.8 & RT & 78.4 & $\begin{array}{l}\mathrm{N}(\text { docetaxel, cisplatin })+\mathrm{C} \\
\text { (cisplatin) }\end{array}$ & C (cisplatin) \\
\hline Kong, 2015 & 200 & - & WHO III-IV & 50 & 63.0 & RT & $66-75$ & C (fluorouracil) & Control \\
\hline \multirow[t]{2}{*}{ Kwong, 2004* } & 219 & 37 & AJCC II-IV,WHO I-III & 45 & 69.1 & RT & 66 & C (uracil, tegafur) & Control \\
\hline & & & & & & & & $\begin{array}{l}\text { A (fluorouracil, cisplatin, } \\
\text { vincristine, } \\
\text { bleomycin, methotrexate) }\end{array}$ & $\begin{array}{l}\mathrm{C} \quad \text { (uracil, } \\
\text { tegafur) }+\mathrm{A} \\
\text { (fluorouracil, } \\
\text { cisplatin } \\
\quad \text { vincristine, } \\
\text { bleomycin, } \\
\text { methotrexate) }\end{array}$ \\
\hline Lai, 2007 & 95 & - & TNM I-IV & 51 & 76.6 & RT & $70-80$ & $\mathrm{C}(\mathrm{CMNa})$ & Control \\
\hline Lee, 2010 & 348 & 60 & WHO III-Ivb & 46 & 72.0 & RT & 68 & \begin{tabular}{lcc|}
$\begin{array}{l}\text { C cisplatin) } \\
\text { (fluorouracil, cisplatin) }\end{array}$ & A \\
\end{tabular} & Control \\
\hline Lee, 2011 & 441 & 73.2 & WHO III-IVb & 46 & 74.0 & RT & 66 & 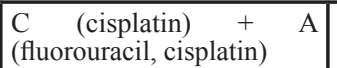 & Control \\
\hline Liang, 2008 & 72 & - & TNM I-IV & & 62.2 & RT & $60-70$ & $\mathrm{C}(\mathrm{CMNa})$ & Control \\
\hline Liao, 2008 & 48 & - & TNM II-IV & 51 & 58.3 & RT & $68-74$ & $\mathrm{C}(\mathrm{CMNa})$ & Control \\
\hline Lin, 2003 & 284 & 65 & WHO I-III & 45 & 71.6 & RT & $70-74$ & C (fluorouracil, cisplatin) & Control \\
\hline Liu, 2006 & 211 & 52 & TNM I-IV & 46 & 88.5 & RT & $68-70$ & $\mathrm{C}(\mathrm{CMNa})$ & Control \\
\hline Liu, 2010 & 44 & - & TNM III-IVa & 51 & 72.7 & RT & $72-74$ & $\mathrm{C}(\mathrm{CMNa})$ & Control \\
\hline Ma, 2001 & 456 & 62 & WHO I-III & 46 & 69.0 & RT & $68-72$ & $\begin{array}{l}\text { N (bleomycin, fluorouracil, } \\
\text { cisplatin) }\end{array}$ & Control \\
\hline Ma, 2009 & 98 & 24 & TNM III-Iva & 48 & 77.6 & RT & 70 & $\begin{array}{l}\mathrm{N} \text { (fluorouracil, cisplatin, } \\
\text { paclitaxel) + } \\
\mathrm{C} \text { (fluorouracil, cisplatin) }\end{array}$ & $\begin{array}{l}\mathrm{C} \\
\text { (fluorouracil, } \\
\text { cisplatin) }\end{array}$ \\
\hline Rossi, 1988 & 229 & - & T1-4,N0-3 & 49 & 70.0 & RT & $60-70$ & $\begin{array}{l}\text { A (vincristine, } \\
\text { cyclophosphamide, } \\
\text { adriamycin) }\end{array}$ & Control \\
\hline Ruste, 2011 & 30 & - & WHO III-IVb & 36 & 62.5 & RT & 70 & $\begin{array}{l}\mathrm{C} \quad \text { (cisplatin) } \\
\text { (fluorouracil, cisplatin) }\end{array}$ & $\begin{array}{l}\mathrm{N} \\
\text { (fluorouracil, } \\
\text { cisplatin) +C } \\
\text { (cisplatin) }\end{array}$ \\
\hline
\end{tabular}




\begin{tabular}{|c|c|c|c|c|c|c|c|c|c|}
\hline Tan, 2008 & 60 & - & TNM I-Iva & 51 & 50.0 & RT & $68-70$ & $\mathrm{C}(\mathrm{CMNa})$ & Control \\
\hline Tan, 2015 & 172 & 40.8 & WHO II-III & 49 & 82.6 & IMRT & 70 & $\begin{array}{l}\mathrm{N} \text { (paclitaxel, gemcitabine) } \\
+\mathrm{C} \text { (cisplatin) }\end{array}$ & C (cisplatin) \\
\hline Wang, 2010 & 66 & - & TNM III & 45 & & RT & $70-74$ & $\mathrm{C}(\mathrm{CMNa})$ & Control \\
\hline Wang, 2014 & 695 & 66.4 & WHO I-II & 45 & 77.7 & IMRT & $67-76$ & C (cisplatin) & Control \\
\hline Wee, $2015^{* *}$ & 83 & 49.4 & WHO I-Iib & 49 & 68.7 & IMRT & 67.5 & C (cisplatin) & $\begin{array}{l}\text { C (cisplatin) } \\
+\quad \text { A } \\
\text { (fluorouracil, } \\
\text { cisplatin) }\end{array}$ \\
\hline & & & & & & & & $\begin{array}{l}\mathrm{N} \text { (docetaxel, fluorouracil, } \\
\text { cisplatin or docetaxel, } \\
\text { cisplatin } \\
\text { or fluorouracil, cisplatin) + } \\
\mathrm{C} \text { (cisplatin) } \\
\end{array}$ & - \\
\hline Wen , 2014 & 60 & - & AJCC III-Ivb & 46 & 57.0 & RT & $60-66$ & C (docetaxel) & Control \\
\hline Wu, 2006 & 40 & - & TNM III-IV & 56 & 75.0 & RT & $70-74$ & $\mathrm{C}(\mathrm{CMNa})$ & Control \\
\hline Wu, 2013 & 115 & 114 & WHO II-III & & & RT & $70-74$ & C (oxaliplatin) & Control \\
\hline Wu, 2014 & 35 & 31.9 & UICC III-Ivb,WHO II-III & 36 & 72.2 & RT & 70 & C (H-R3) & Control \\
\hline $\mathrm{Xu}, 2014$ & 338 & 60 & AJCC III-Ivb & 49 & 74.1 & RT & $70-76$ & $\begin{array}{l}\mathrm{N} \text { (fluorouracil, cisplatin) } \\
+\mathrm{A} \text { (fluorouracil, cisplatin) }\end{array}$ & $\begin{array}{l}\text { C } \\
\text { (fluorouracil, } \\
\text { cisplatin) + } \\
\text { A } \\
\text { (fluorouracil, } \\
\text { cisplatin) } \\
\end{array}$ \\
\hline $\mathrm{Xu}, 2015$ & 86 & 37.4 & UICC II-IV & 51 & 72.1 & IMRT & 66 & C (cisplatin) & Control \\
\hline Yang, 2007 & 60 & - & T1-4N0-3M0 & 41 & 66.7 & RT & $60-70$ & $\mathrm{C}(\mathrm{CMNa})$ & Control \\
\hline Yang, 2012 & 60 & 3 & TNM II-IV & 63 & 73.3 & RT & 72 & $\mathrm{C}(\mathrm{CMNa})$ & Control \\
\hline Yi, 2014 & 333 & - & WHO III-IV & 47 & 73.9 & IMRT & $70-74$ & C (cisplatin) & Control \\
\hline Zeng, 2014 & 234 & 22 & WHO II-III & 48 & 86.0 & RT & 70 & C (cisplatin) & Control \\
\hline Zhang, 2005 & 115 & 24 & WHO II-III,AJCC III-IV & 46 & 67.8 & RT & $70-74$ & C (oxaliplatin) & Control \\
\hline Zhang, 2008 & 100 & - & TNM III-IV & & & RT & $68-70$ & $\mathrm{C}(\mathrm{CMNa})$ & Control \\
\hline Zhang, 2008 & 45 & - & TNM III-IV & 41 & 80.0 & RT & $70-74$ & $\mathrm{C}(\mathrm{CMNa})$ & Control \\
\hline Zhang, 2015 & 799 & 55.27 & WHO I-III & 46 & 73.0 & IMRT & 60 & $\begin{array}{l}\mathrm{N} \text { (docetaxel, paclitaxel, } \\
\text { cisplatin or docetaxel, } \\
\text { paclitaxel, cisplatin, } \\
\text { fluorouracil) + C (cisplatin) }\end{array}$ & C (cisplatin) \\
\hline Zhou, 2011 & 60 & - & $\mathrm{T} 2 \mathrm{~N} 2 \mathrm{M} 0$ & 46 & 80.0 & RT & $70-74$ & $\mathrm{C}(\mathrm{CMNa})$ & Control \\
\hline
\end{tabular}

Kwong, 2004*, four arms study; Wee, 2015**, three arms study; Abbreviations: AJCC, American Joint Committee on Cancer; WHO, World Health Organization; UICC, International Union Against Cancer; TNM, T, Tumor, N, regional lymph node, M, metastasis; RT, radiotherapy; IMRT, intensity-modulated radiotherapy; A, Adjuvant chemotherapy; C, Concurrent chemotherapy; N, Neoadjuvant chemotherapy; CMNa, sodium glycididazole.

two nodes indicated the number of included direct evidences.

\section{Result of conventional MA}

Direct comparisons from conventional MA were shown in Table 2. NPC patients with C were associated with significantly decreased $\mathrm{HR}$ and increased probability of CR compared with the control group. The above trend was also presented in survival benefit between patients with $\mathrm{C}+\mathrm{A}$ and those in the control group. Besides, patients with $\mathrm{N}+\mathrm{C}$ exhibited an average increase of $9 \%$ in the 3 -year $\mathrm{OS}(\mathrm{HR}=1.09,95 \% \mathrm{CI}=1.01-1.16)$ in relation to those with $\mathrm{C}+\mathrm{A}$.

\section{Result of NMA}

Several trends were revealed by mixed-treatment comparisons, as recorded in Table 3 and shown graphically in Figure S1 and Figure S2. In the outcomes of 5-year OS, five therapies were associated with a significantly reduced HR compared with the control group (C: HR $=0.70,95 \%$ CI: $0.59-0.85 ; \mathrm{C}+\mathrm{A}: \mathrm{HR}=0.64,95 \% \mathrm{CrI}$ : $0.52-0.79 ; \mathrm{N}+\mathrm{C}: \mathrm{HR}=0.74,95 \%$ CrI: 0.57-0.96; N: HR $=0.80,95 \%$ CI: $0.65-0.98 ; \mathrm{N}+\mathrm{A}: \mathrm{HR}=0.54,95 \%$ CrI: 0.31-0.93). C, C+A and N+A also presented a decreased HR compared with A. With respect to 3-year, the result was similar to that during the five year period versus the control group. Similarity occurred in comparisons with A. 
Considering 1-year OS, significant result was obtained in the primary comparisons with control group and A, along with wider interval distributions. Additional significant result was achieved when we compared $\mathrm{C}, \mathrm{C}+\mathrm{A}$ and $\mathrm{N}+\mathrm{C}$ with $\mathrm{N}(\mathrm{C}: \mathrm{HR}=0.44,95 \% \mathrm{CrI}: 0.21-0.90 ; \mathrm{C}+\mathrm{A}: \mathrm{HR}=$ 0.51, 95\% CrI: $0.27-0.96 ; \mathrm{N}+\mathrm{C}: \mathrm{HR}=0.44,95 \% \mathrm{CrI}$ : 0.21-0.94), which may indicate the difference in the short-

\section{5 years overall survival}

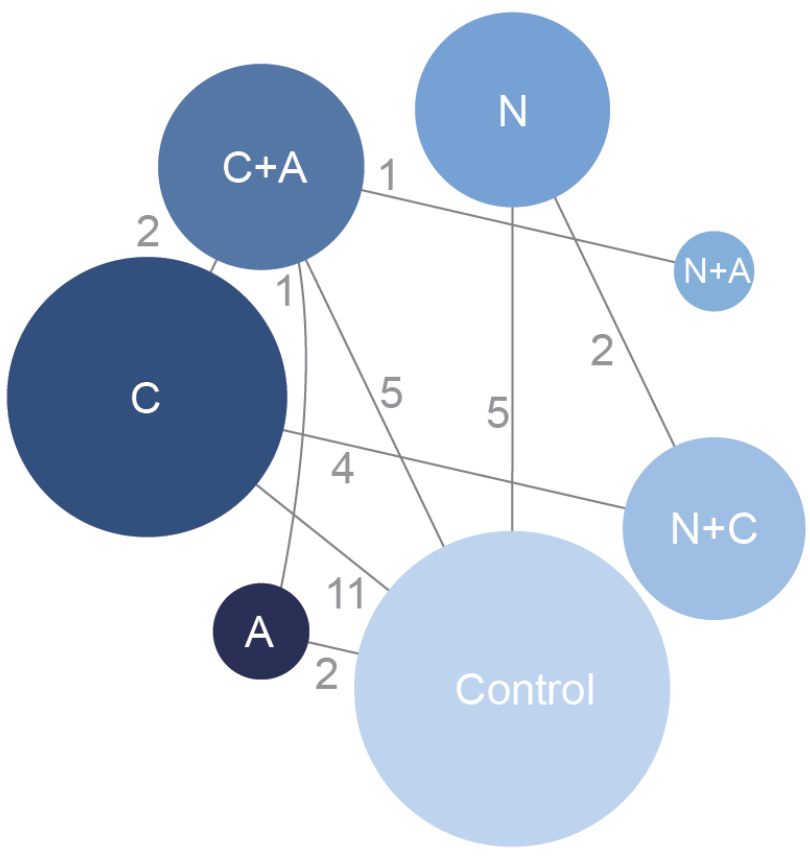

1 year overall survival

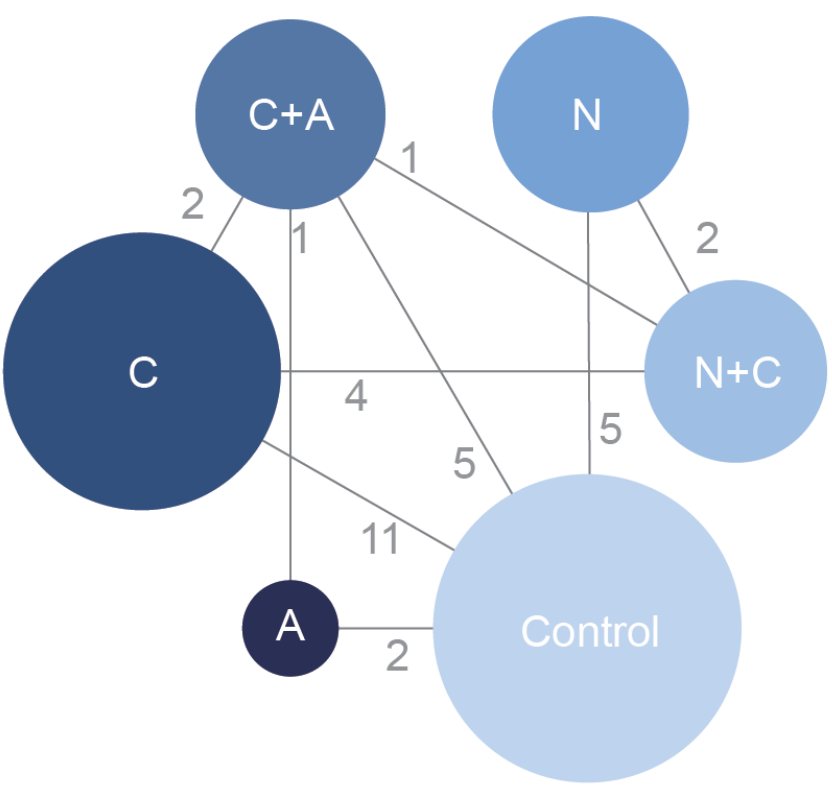

term performance. According to the result, we found that there was consistency among 1-year, 3-year and 5-year OS status. Furthermore, NPC patients with $\mathrm{C}, \mathrm{C}+\mathrm{A}, \mathrm{N}+\mathrm{C}$ and $\mathrm{N}$ appeared to have significantly higher possibility of $\mathrm{CR}$ compared with the control group.

\section{3 years overall survival}

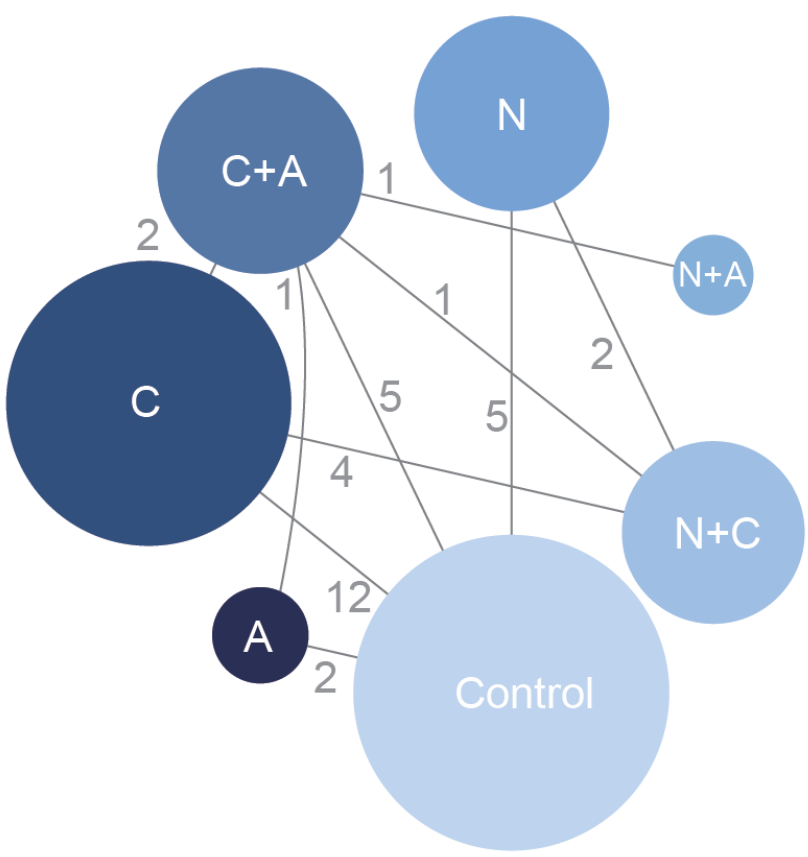

Complete response

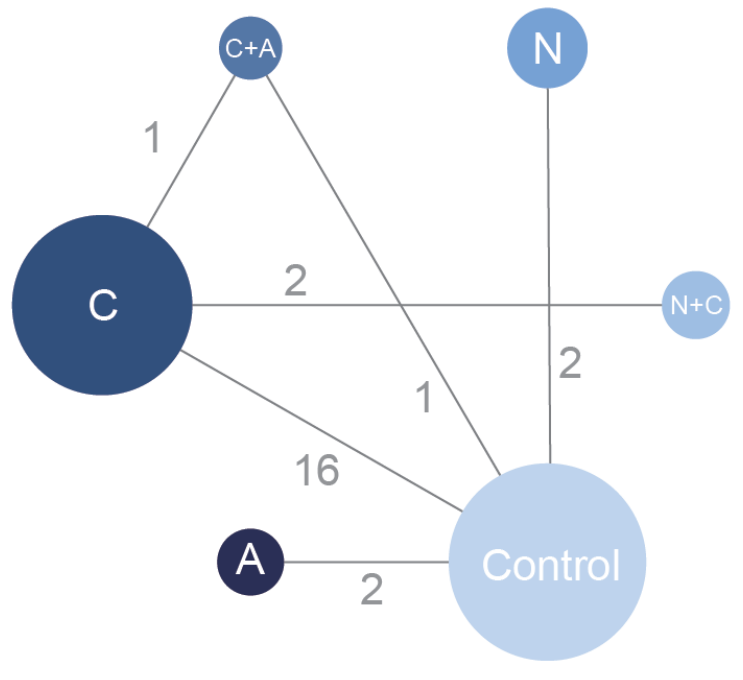

Figure 2: The network plot of included interventions. 
Table 2: Meta-analysis results for pair-wise comparisons.

\begin{tabular}{|l|l|c|c|c|c|}
\hline Intervention 1 & Intervention 2 & 5 years OS & 3 years OS & 1 years OS & CR \\
\hline $\mathbf{A}$ & Control & $1.22(0.85,1.75)$ & $1.20(0.81,1.80)$ & $1.16(0.59,2.28)$ & $1.11(0.86,1.43)$ \\
\hline $\mathbf{C}$ & Control & $0.68(0.52,0.90)$ & $0.66(0.48,0.90)$ & $0.32(0.15,0.67)$ & $1.16(1.06,1.28)$ \\
\hline $\mathbf{C}+\mathbf{A}$ & Control & $0.65(0.53,0.80)$ & $0.62(0.47,0.81)$ & $0.46(0.26,0.81)$ & $1.23(0.81,1.88)$ \\
\hline $\mathbf{N}$ & Control & $0.84(0.69,1.02)$ & $0.86(0.69,1.06)$ & $0.96(0.63,1.48)$ & $1.04(0.89,1.21)$ \\
\hline $\mathbf{C}+\mathbf{A}$ & $\mathbf{A}$ & $0.74(0.36,1.55)$ & $0.69(0.26,1.84)$ & $1.47(0.03,80.96)$ & - \\
\hline $\mathbf{C}+\mathbf{A}$ & $\mathbf{C}$ & $0.80(0.50,1.29)$ & $0.76(0.40,1.45)$ & $1.10(0.23,5.20)$ & $1.09(0.72,1.66)$ \\
\hline $\mathbf{N}+\mathbf{A}$ & $\mathbf{C}+\mathbf{A}$ & $0.84(0.53,1.34)$ & $1.06(0.27,4.08)$ & - & - \\
\hline $\mathbf{N}+\mathbf{C}$ & $\mathbf{C}$ & $0.94(0.74,1.21)$ & $0.82(0.43,1.56)$ & $0.59(0.14,2.53)$ & $1.04(0.83,1.30)$ \\
\hline $\mathbf{N}+\mathbf{C}$ & $\mathbf{C}+\mathbf{A}$ & - & $1.09(1.01,1.16)$ & $0.89(0.38,2.05)$ & - \\
\hline $\mathbf{N}+\mathbf{C}$ & $\mathbf{N}$ & $1.04(0.63,1.71)$ & $1.10(0.54,2.21)$ & $0.82(0.15,4.47)$ & - \\
\hline
\end{tabular}

Abbreviation: A, Adjuvant chemotherapy; C, Concurrent chemotherapy; N, Neoadjuvant chemotherapy

\section{Ranking of SUCRA}

Firstly, the SUCRA values revealing the rank of abovementioned therapies in different outcomes were recorded in Table 4. Overall, $\mathrm{C}$ together with the combined approaches of $\mathrm{C}+\mathrm{A}$ and $\mathrm{N}+\mathrm{C}$ exhibited to be the most competitive therapies with respect to prognostic outcomes and complete response according to the SUCRA values. Another noteworthy therapy was $\mathrm{N}+\mathrm{A}$, it was the most
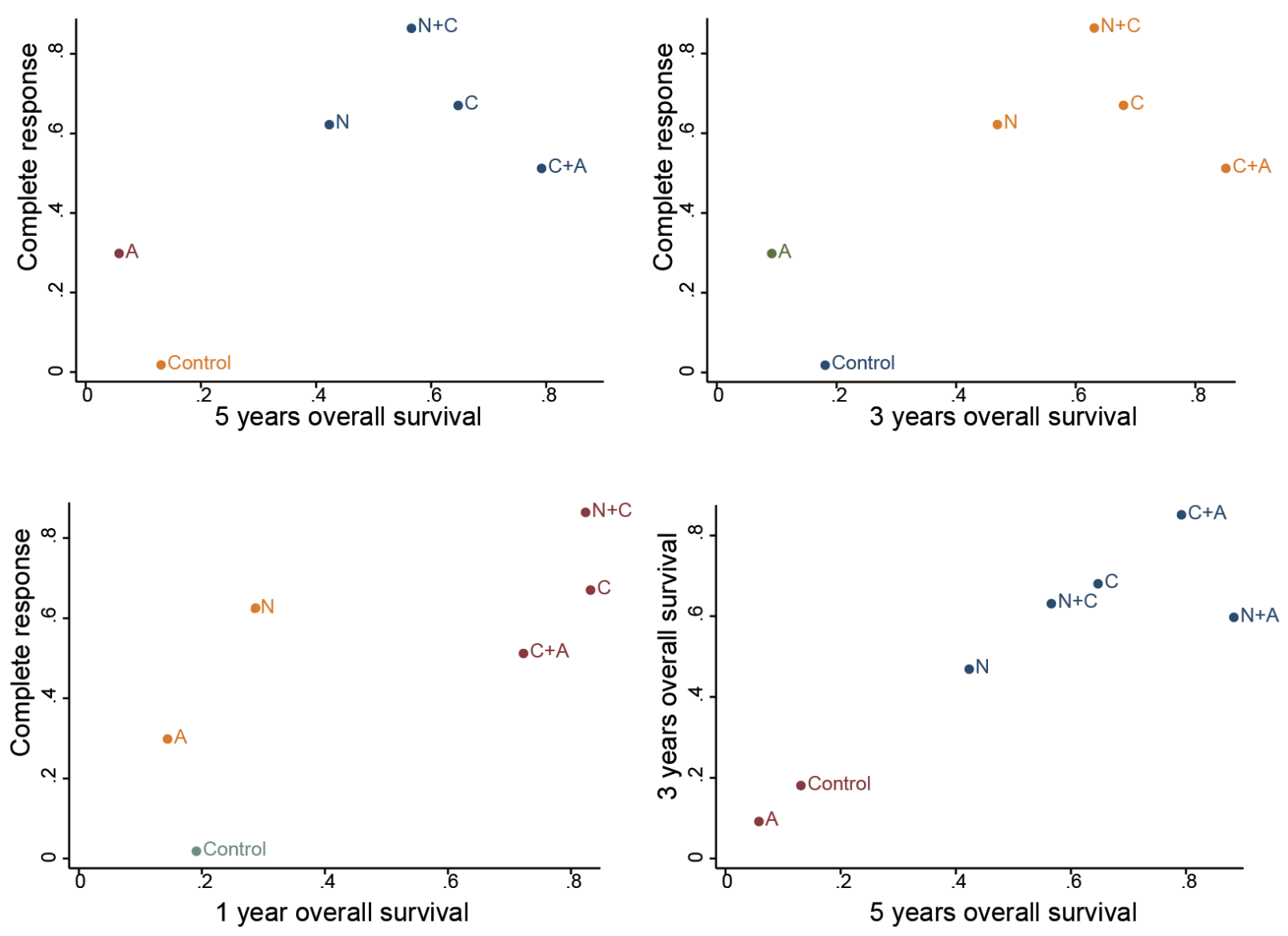

Figure 3: Clustered ranking plot of the network. The plot is based on cluster analysis of surface under the cumulative ranking curves (SUCRA) values. Each plot shows SUCRA values for two outcomes. Each color represents a group of treatments that belong to the same cluster. Treatments lying in the upper right corner are more effective and safe than the other treatments. 
Table 3: Network meta-analysis results for long-term and short-term prognoses.

\begin{tabular}{|c|c|c|c|c|c|c|c|}
\hline & \multicolumn{7}{|c|}{3 years $\mathrm{OS}$} \\
\hline \multirow{7}{*}{5 years OS } & Control & $1.16(0.79,1.70)$ & $0.70(0.55,0.90)$ & $0.64(0.52,0.80)$ & $0.80(0.65,0.99)$ & $0.68(0.17,2.70)$ & $0.72(0.56,0.91)$ \\
\hline & $1.13(0.79,1.60)$ & A & $0.61(0.39,0.95)$ & $0.56(0.36,0.86)$ & $0.69(0.45,1.07)$ & $0.59(0.14,2.45)$ & $0.62(0.40,0.96)$ \\
\hline & $0.70(0.59,0.85)$ & $0.62(0.42,0.93)$ & C & $0.92(0.70,1.20)$ & $1.14(0.84,1.55)$ & $0.97(0.24,3.88)$ & $1.02(0.77,1.34)$ \\
\hline & $0.64(0.52,0.79)$ & $0.57(0.39,0.83)$ & $0.91(0.70,1.18)$ & $\mathrm{C}+\mathrm{A}$ & $1.24(0.95,1.63)$ & $1.06(0.27,4.12)$ & $1.11(0.95,1.31)$ \\
\hline & $0.80(0.65,0.98)$ & $0.71(0.47,1.06)$ & $1.13(0.88,1.45)$ & $1.25(0.93,1.67)$ & $\mathbf{N}$ & $0.85(0.21,3.41)$ & $0.89(0.68,1.17)$ \\
\hline & $0.54(0.31,0.93)$ & $0.48(0.25,0.90)$ & $0.77(0.44,1.35)$ & $0.84(0.51,1.39)$ & $0.68(0.38,1.21)$ & $\mathbf{N}+\mathbf{A}$ & $1.05(0.27,4.15)$ \\
\hline & $0.74(0.57,0.96)$ & $0.65(0.42,1.01)$ & $1.05(0.82,1.33)$ & $1.15(0.83,1.60)$ & $0.92(0.71,1.20)$ & $1.36(0.75,2.48)$ & $\mathrm{N}+\mathrm{C}$ \\
\hline & \multicolumn{7}{|c|}{ CR } \\
\hline \multirow{7}{*}{1 year OS } & Control & $1.73(0.82,3.78)$ & $3.06(2.25,4.28)$ & $2.46(1.16,6.40)$ & $2.89(1.09,8.98)$ & - & $4.35(1.89,11.86)$ \\
\hline & $1.12(0.57,2.18)$ & A & $1.76(0.77,3.97)$ & $1.41(0.50,4.86)$ & $1.68(0.47,6.66)$ & - & $2.51(0.83,8.63)$ \\
\hline & $0.40(0.21,0.73)$ & $0.35(0.14,0.88)$ & $\mathrm{C}$ & $0.81(0.36,2.04)$ & $0.95(0.34,3.01)$ & - & $1.43(0.64,3.52)$ \\
\hline & $0.46(0.28,0.76)$ & $0.42(0.18,0.95)$ & $1.17(0.59,2.34)$ & $\mathrm{C}+\mathrm{A}$ & $1.20(0.30,4.28)$ & - & $1.79(0.52,5.70)$ \\
\hline & $0.91(0.60,1.37)$ & $0.81(0.37,1.78)$ & $2.29(1.11,4.72)$ & $1.95(1.04,3.65)$ & $\mathbf{N}$ & - & $1.51(0.36,6.03)$ \\
\hline & - & - & - & - & - & $\mathbf{N}+\mathbf{A}$ & \\
\hline & $0.40(0.20,0.80)$ & $0.36(0.14,0.93)$ & $1.01(0.48,2.11)$ & $0.86(0.45,1.66)$ & $0.44(0.21,0.94)$ & - & $\mathbf{N}+\mathbf{C}$ \\
\hline
\end{tabular}

Abbreviation: A, Adjuvant chemotherapy; C, Concurrent chemotherapy; N, Neoadjuvant chemotherapy

5 years overall survival, 3 years overall survival, 1 year overall survival, represented by hazard ratio (HR) and 95\% credible interval $(\mathrm{CrI})$, and complete response represented by odds ratio (OR) and 95\% credible interval (CrI). In lower half of the table, row treatments are compared against column treatments, whereas in the upper half, column treatments are compared against row treatments.

efficacy combination in 5y-OS outcomes. Then, the result was well displayed by the cluster analysis in Figure 3, in which the included therapies were categorized into different groups based on their SUCRA values. Cluster analysis suggested that the above three chemoradiotherapy appeared to be divided into the most efficacious group located in the upper right corner of the cluster plots. On

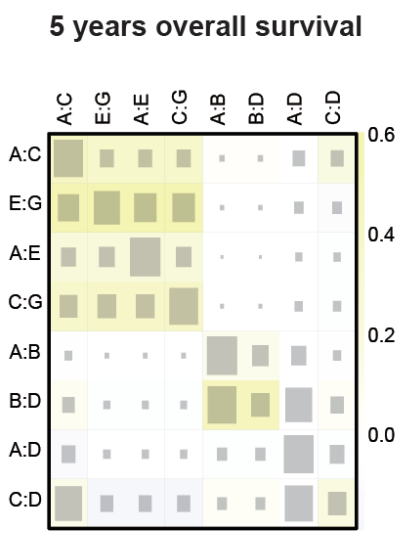

3 years overall survival

山辶寸

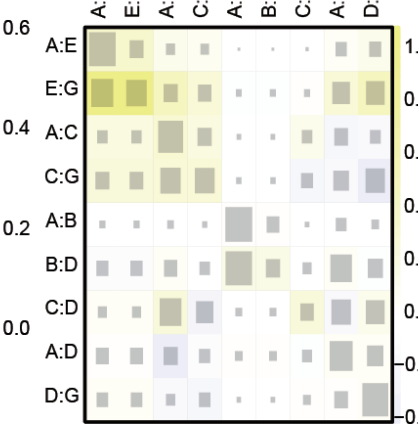

top of that, the cluster plots showed that the results of included outcomes were substantially similar in this NMA.

\section{Consistency between direct and indirect evidence}

Since the consistency model was introduced in the NMA, this assumption was supposed to be evaluated in
A - Control B - Concurrent chemotherapy
F - Neoadjuvant + Adjuvant chemotherapy

C - Adjuvant chemotherapy

G - Neoadjuvant + Concurrent chemotherapy
1 year overall survival

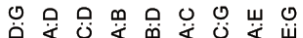

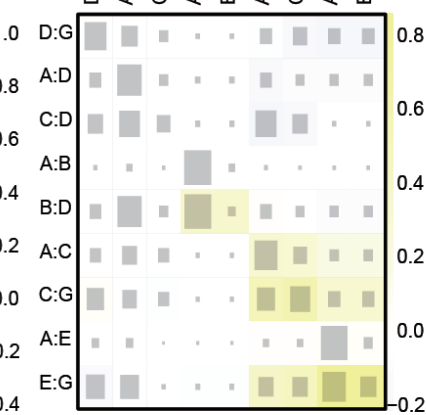

D - Concurrent + Adjuvant chemotherapy

E - Neoadjuvant chemotherapy
Complete response

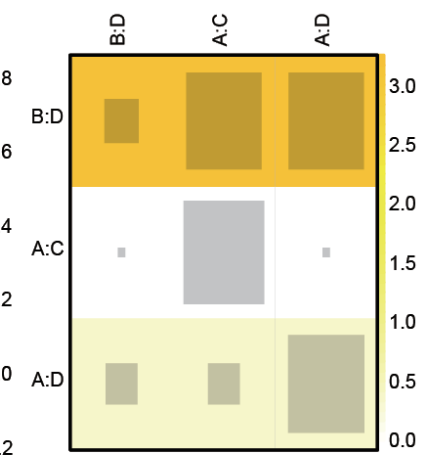

0.0

Figure 4: Net heat plot. Warm color in the net heat plot indicates that significant inconsistency may arise from a specific design or comparison and this trend is illustrated by the intensity of the color. 
Table 4: Surface under the cumulative ranking curve (SUCRA) values of each intervention.

\begin{tabular}{|l|c|c|c|c|}
\hline \multicolumn{1}{|c|}{ Interventions } & 5 years OS & 3 years OS & 1 years OS & CR \\
\hline Control & 0.131 & 0.181 & 0.191 & 0.018 \\
\hline $\mathbf{A}$ & 0.058 & 0.092 & 0.144 & 0.298 \\
\hline $\mathbf{C}$ & 0.647 & 0.680 & 0.832 & 0.670 \\
\hline $\mathbf{C}+\mathbf{A}$ & 0.792 & 0.851 & 0.723 & 0.512 \\
\hline $\mathbf{N}$ & 0.423 & 0.469 & 0.285 & 0.622 \\
\hline $\mathbf{N}+\mathbf{A}$ & 0.883 & 0.597 & - & - \\
\hline $\mathbf{N}+\mathbf{C}$ & 0.566 & 0.631 & 0.824 & 0.864 \\
\hline
\end{tabular}

Abbreviation: A, Adjuvant chemotherapy; C, Concurrent chemotherapy; N, Neoadjuvant chemotherapy

this NMA. As suggested by the net heat plot in Figure 4, no significant inconsistency appeared in the comparison with respect to the survival outcomes. However, substantial inconsistency was observed from the comparison between $\mathrm{C}$ and $\mathrm{C}+\mathrm{A}$ under the endpoint of $\mathrm{CR}(P=0.041)$, as was shown in the node splitting plot (Figure $\mathrm{S} 3$ ).

\section{DISCUSSION}

In this study, a comprehensive and quantitative comparison among the existed chemotherapies given as the integral part of radiotherapy in patients with NPC was successfully conducted. This evaluation presented both direct and indirect evidence through pairwise meta-analysis and mixed meta-analysis. The statistical differences presented in the results would lead us to give an appropriate estimate and find out the optimal clinical choices.

As the SUCRA results revealed, therapeutic strategies based on concurrent chemoradiotherapy, including concurrent chemoradiotherapy alone or combined with adjuvant or neoadjuvant chemotherapy, were recommended as the first-line therapies, when the characteristics of individuals are not clarified. It was reported that platinum-based concurrent chemoradiotherapy had been accepted by the National Comprehensive Cancer Network as the standard recommendation for locally advanced NPC since the Intergroup 0099 study was published in 1998 [7]. And its superiority in clinical performance over traditional radiotherapy had been demonstrated in subsequent RCT studies [8] and MAs [9, 10]. It was reported that tissue fibrosis and vascular changes of tumor in locally recurrent NPC attributed to its poor sensitivity to radiotherapy [11]. However, chemotherapy was found to be a highly responded therapy instead [12]. Thus concurrent chemotherapy provided a reinforced efficacy by increasing the sensitivity of NPC toward radiotherapy. When comparing the add-on chemotherapies based on concurrent chemoradiotherapy $(\mathrm{C}+\mathrm{A}$ and $\mathrm{N}+\mathrm{C})$, no head-to-head comparison was conducted according to the retrieve results. Besides, no statistically significant result had been pooled, with merely marginal differences. Additionally, the survival benefit in the documented records was as ambiguous as the NMA result, meaning that the addition of adjuvant or neoadjuvant chemotherapy had not been significantly translated to the improvement in overall survival benefit and complete response rate.

Among those chemotherapies binding with conventional radiotherapy, the number of included publications was limited, which meant further evidence was still required to give a more accurate evaluation. Neoadjuvant chemotherapy, followed by radiotherapy alone with adjuvant chemotherapy, is given an appreciable preference, especially in the outcomes of 5 -year overall survival rate, although recorded by merely one publication, which is documented as a long-term, updated result reported by Xu et al [13]. Undoubtedly, the relevant ranking was lack of solid credibility. However, according to this document, this kind of chemotherapy added to traditional radiotherapy was comparable with concurrent plus adjuvant chemoradiotherapy in the aspect of overall survival benefits, and was considered as a potential alternative to the latter. As a result, this potentially preferable therapy could be a research focus of further RCT studies. The separated neoadjuvant chemotherapy followed by radiotherapy was documented by 5 publications, among which the latest one was updated in 2002 by Hareyama et al [14]. It had a middle position in the SUCRA ranking score and presented a moderate performance in the including outcomes. However, its limitation was reported as a low proportion of patient response [15], failure to achieve the primary goal of eradicating distant micro-metastases because of non-sufficient dosage [16] or a failed translation from the reduction in local relapses into an overall survival advantage due to local or regional recurrence [16]. As a result, almost no further researches were reported and neoadjuvant chemotherapy became an integral part of concurrent chemoradiotherapy. Adjuvant chemotherapy plus radiotherapy exhibits to be not advantageous in the case of improving overall survival and tent to result in more complete response than the control group of radiotherapy. The included publication pooled 
no significant improvement, just consistent with our NMA. It was criticized for the regimen was thought to be suboptimal [17] or dose-intensity was reduced [17]. Despite the low ranking in our NMA result, adjuvant chemotherapy was reported to be efficacious in decreasing the chance of systemic relapse [18]. Consequently, a more reasonable estimate would be given if outcomes were taken into consideration.

Radiotherapy alone seemed to be the last choice for patients with NPC. Although it was considered useful in the early-stage NPC, the low cure rate made it unsatisfying $[19,20]$, which was coincident with the result that we had demonstrated in NMA. Especially in those with locally recurrent NPC, re-irradiation is associated with severe complications at high doses, which could even be the primary cause of death [21]. The confirmed therapeutic advantage of concurrent chemoradiotherapy over radiotherapy was the result of the fact that most included trials were comparing with the conventional technique. However, there had been development in this traditional therapy. Intensity-modulated radiotherapy (IMRT), a modern radiotherapy technique, had been applied in more studies, especially in the recent trials [2224]. In this case, the tumor volumes were delineated more accurately, so better dose distribution could be adopted [22]. Thus, significant improvement has been diluted when patients were given the additional chemotherapy. Besides, three-dimensional conformal radiation therapy (3D-CRT) was another developed technique, providing improved calculation, shielding, and the classic field arrangement compared with the traditional 2D technique [25]. The primary purpose of chemotherapy is to increase the disease control locally and distantly [26, 27]. And its advantageous clinical performance had been proved in a large quantity of trials. Nevertheless, the tendency had emerged that advanced radiotherapy technology could be alternative to concurrent chemoradiotherapy.

Though successfully conducted, a number of limitations still existed in this NMA. First, the detailed information that was directly related to survival rate, such as distant metastasis, and the toxicity of chemotherapy with the corresponding adverse responses was not included. Though most adverse responses were manageable and uncomplicated, and not associated with death, chemotherapy was still poorly tolerable. Moreover, undoubtedly the addition of chemotherapy was responsible for some severe events. For example, the increase of hematologic events in patient with neoadjuvant or adjuvant chemotherapy had been reported [23]. Second, as we had mentioned above, specific comparison was limited due to the lack of available head-to-head trials, especially among those chemotherapies based on traditional radiotherapy. It was insufficient to pool a clear result and give a critical conclusion. Finally, we did not use the detailed data of individual patients. In fact, the included patients are belonging to different stages of
NPC sufferers. And they were characterized by different symptoms, so researchers were tent to divide them into subgroups. It had been proposed that radiotherapy alone can be sufficient treatment for early-stage NPC patients. Combined concurrent chemoradiotherapy with adjuvant chemotherapy was recommended for those at intermediate risk stage. Aggressive neoadjuvant chemotherapy, followed by CCRT and adjuvant chemotherapy may be the choice for high-risk patients [28].

In conclusion, in view of survival rate and complete response, concurrent chemoradiotherapy with adjuvant chemotherapy $(\mathrm{C}+\mathrm{A})$, concurrent chemoradiotherapy with neoadjuvant chemotherapy $(\mathrm{N}+\mathrm{C})$ and concurrent chemoradiotherapy (C) itself was considered as the firstline treatment according to the NMA result. Even so, it was worth noting that the advanced modern radiotherapy technique had the potential to be an alternative. Cautious and approaches based on evidence should be maintained. Guidance from our NMA was recommended to be integral with individual characteristics.

\section{MATERIALS AND METHODS}

\section{Search strategy and selection criteria}

Literature search was conducted in electronic databases by two independent reviewers. Multiple resources were searched accordingly for the purpose of preventing selection bias: China National Knowledge Internet (CNKI), PubMed and Embase. Literature search was not restricted to any language or type of publication. The following key terms accompanied with their entry terms were used to build a searching query: "nasopharyngeal neoplasms", "radiotherapy", "chemotherapy", "chemoradiotherapy" and etc. The searching results were updated in September 2016.

Studies were included if they were randomized controlled trials (RCT) which combined at least one chemotherapy regimen with radiotherapy. Besides that, patients in the included studies [1-11, 13, 14, 17, 24, 2965] were diagnosed with NPC (stage I to IV) according to the criteria set by the American Joint Committee on Cancer (AJCC), the World Health Organization (WHO), the International Union against Cancer (IUAC) and the tumor node metastasis (TNM) staging system.

\section{Data extraction}

The process of data extraction was accomplished by two independent reviewers. The following study characteristics were included for each research: (1) the basic information of the research, including the first author, published year, the size of samples and the followup duration; (2) the patients characteristics, including 
tumor stage, age and sex; (3) the regimens, including the type and dose of radiotherapy and the interventions for comparison; (4) outcomes, including 1-year, 3-years and 5-years overall survival (OS) and complete response (CR). If the same study had been published for more than once, the one with longer following-up duration would be preferred. risk of bias was also evaluated by using the famous Cochrane risk of bias assessment tool [54]. Each study was classified as having high, low or unclear risk of bias.

\section{Statistical analysis}

Since not only the short-term efficacy of chemoradiotherapies but also their long-term efficacy in NPC patients was concerned in this NMA, the 3-year and 5-year OS were selected as major outcomes whereas the 1-year and CR were selected as secondary outcomes. We used the hazard ratio (HR) and its 95\% confidence intervals (CIs) to measure the relative efficacy between two comparators when survival data were synthesized from individual studies. A significantly increased HR (HR $>1$ ) suggested that one therapy may be less efficacious than another and vice versa. Besides, the statistics of odds ratio (OR) and its 95\% (CIs) were also computed when CR data were synthesized from individual studies. The random-effects model was introduced for pair-wise meta-analysis, which generated summary statistics for every direct comparison. We used $I^{2}$ statistics to evaluate the between-study heterogeneity, in which $I^{2}>50 \%$ was considered high heterogeneity. Then R 3.2.3 and STATA 13.0 were adopted to conduct NMA. Summary statistics and their $95 \%$ credible intervals (CrIs) were computed by the approach of NMA. Furthermore, the cumulative ranking probability of each chemoradiotherapy was computed so that chemoradiotherapy can be ranked with respect to each outcome. Additionally, the net heat plot was created by the software to evaluate the consistency between direct and indirect comparison. Warm color in the net heat plot indicates that significant inconsistency may arise from a specific design or comparison and this trend is illustrated by the intensity of the color. Besides, the node splitting method was adopted to test the presence of significant inconsistency for each comparison and $P$-value $<0.05$ concludes the significance of inconsistency. Finally, chemoradiotherapies were categorized into different groups by using the approach of cluster analysis.

\section{Abbreviations}

OS-overall survival; CR-complete response; NPCnasopharyngeal carcinoma; NMA-network meta-analysis; HR-hazard ratio; C-concurrent chemoradiotherapy; A-adjuvant chemotherapy; N- neoadjuvant chemotherapy; $\mathrm{C}+\mathrm{A}$-concurrent chemoradiotherapy with adjuvant chemotherapy; $\mathrm{C}+\mathrm{N}$-concurrent chemoradiotherapy with neoadjuvant chemotherapy; N+A-neoadjuvant chemotherapy with adjuvant chemotherapy; CIsconfidence intervals; OR-odds ratio; RT-radiotherapy; RCTs-randomized clinical trials; CNKI-China National Knowledge Internet; AJCC-American Joint Committee on Cancer; WHO-World Health Organization; IUACInternational Union against Cancer; TNM-tumor node metastasis.

\section{Author contributions}

HJ, WP and TYY: Literature search, data extraction and manuscript writing; LSL, XCB and LS: Statistical analysis; ZJF, XJ and ZSP: Manuscript revision and experimental design. HJ, WP and ZSP are responsible for the overall content as the guarantor. All authors have read and approved the final manuscript.

\section{CONFLICTS OF INTERESTS}

All authors declare no compete interests.

\section{FINANCIAL SUPPORTING}

This research is supported by The National Natural Sicence Foundation of China (81302355), The National Natural Sicence Foundation of China (81201740) and Xiangya Famous Doctors Foundation.

\section{REFERENCES}

1. Liang R, Shen X, Chen ZH, Yu ZH. Radiosensitization of CMNa of Locally Recurrent Nasopharyngeal Cancer. Tumor Prevention and Treatment. 2008; 21:162-164.

2. Liao SH. CMNa on clinical effect of nasopharyngeal carcinoma radiotherapy sensitization. Guangxi Medical Journal. 2008; 30:27-28.

3. Liu SB, Li M, Pan YF, Liang BH. Clinical study of CMNa combined with radiotherapy on advanced nasopharyngeal carcinoma. Modern Oncology. 2010; 18:2137-2138.

4. Ma HM, Yuan X, Huang YL, Lin YF, Liu CX. Paclitaxel and cisplatin, 5 -fluorouracil (TPF) programme neoadjuvant chemotherapy for advanced nasopharyngeal cancer. Modern Oncology. 2009; 17:1233-1235.

5. Tan JM, Li MY, Lin DR. Radiosensitization of Sodium Glycididazole in re-radiotherapy for local current nasopharyngeal carcinoma. Modern Medicine Journal of China. 2008; 10:25-27.

6. Wang YB, Tong YH, Luo JW, Luo DP. Clinical Observation of Radiotherapy combined with $\mathrm{CMNa}$ in Stage III nasopharyngeal carcinoma. Strait Pharmaceutical Journal. 2010; 22:172-174.

7. Yang FJ. (2007). Clinical analysis of re-irradiation plus 
$\mathrm{CMNa}$ to recurrent nasopharyngeal carcinoma. Central South University).

8. Yang Y, Tuo XL, Huang JP, Sun WB. CMNa combined radiotherapy curative effect in senile nasopharyngeal carcinoma. Chinese Journal of Gerontology. 2012; 32:28902891.

9. Zhang LW, Zhao J. Clinical study of the short-term curative effect of CMNa on nasopharyngeal cancer radiotherapy. Journal of Clinical and Experimental Medicine. 2008; 46:39-40.

10. Zhang SB, Jiang QH, Chen M, Zeng WQ. Observation and nursing for $\mathrm{CMNa}$ with radiation in the treatment of nasopharyngeal carcinoma. Tumor prevention and treatment. 2008; 21:315-317.

11. Zhou WH, Pan XH, Bi XX, Jiang XC. Effect Assessment of Sodium glycididazo Combined with Radiation Treatment of Nasopharyngeal Cancer. Journal of Aerospace Medicine. 2011; 22:389-390.

12. Tannock I, Payne D, Cummings B, Hewitt K, Panzarella T. Sequential chemotherapy and radiation for nasopharyngeal cancer: absence of long-term benefit despite a high rate of tumor response to chemotherapy. Journal of clinical oncology. 1987; 5:629-634.

13. Xu T, Zhu G, He X, Ying H, Hu C. A phase III randomized study comparing neoadjuvant chemotherapy with concurrent chemotherapy combined with radiotherapy for locoregionally advanced nasopharyngeal carcinoma: Updated long-term survival outcomes. Oral oncology. 2014; 50:71-76.

14. Hareyama M, Sakata K, Shirato H, Nishioka T, Nishio M, Suzuki K, Saitoh A, Oouchi A, Fukuda S, Himi T. A prospective, randomized trial comparing neoadjuvant chemotherapy with radiotherapy alone in patients with advanced nasopharyngeal carcinoma. Cancer. 2002; 94:2217-2223.

15. Rosenthal DI, Pistenmaa DA, Glatstein E. A review of neoadjuvant chemotherapy for head and neck cancer: partially shrunken tumors may be both leaner and meaner. International journal of radiation oncology, biology, physics. 1994; 28:315-320.

16. Ma J, Mai HQ, Hong MH, Min HQ, Mao ZD, Cui NJ, Lu TX, Mo HY. Results of a prospective randomized trial comparing neoadjuvant chemotherapy plus radiotherapy with radiotherapy alone in patients with locoregionally advanced nasopharyngeal carcinoma. Journal of clinical oncology. 2001; 19:1350-1357.

17. Kwong DL, Sham JS, Au GK, Chua DT, Kwong PW, Cheng AC, Wu PM, Law MW, Kwok CC, Yau CC, Wan KY, Chan RT, Choy DD. Concurrent and adjuvant chemotherapy for nasopharyngeal carcinoma: a factorial study. Journal of clinical oncology. 2004; 22:2643-2653.

18. Chi KH, Chang YC, Guo WY, Leung MJ, Shiau CY, Chen SY, Wang LW, Lai YL, Hsu MM, Lian SL, Chang CH, Liu TW, Chin YH, et al. A phase III study of adjuvant chemotherapy in advanced nasopharyngeal carcinoma patients. International journal of radiation oncology, biology, physics. 2002; 52:1238-1244.

19. Fandi A, Altun M, Azli N, Armand JP, Cvitkovic E. Nasopharyngeal cancer: epidemiology, staging, and treatment. Semin Oncol. 1994; 21:382-397.

20. Lee AW, Poon YF, Foo W, Law SC, Cheung FK, Chan DK, Tung SY, Thaw M, Ho JH. Retrospective analysis of 5037 patients with nasopharyngeal carcinoma treated during 1976-1985: overall survival and patterns of failure. International journal of radiation oncology, biology, physics. 1992; 23:261-270.

21. Zheng XK, Ma J, Chen LH, Xia YF and Shi YS. Dosimetric and clinical results of three-dimensional conformal radiotherapy for locally recurrent nasopharyngeal carcinoma. Radiotherapy and oncology. 2005; 75:197-203.

22. Xu T, Shen C, Zhu G, Hu C. Omission of Chemotherapy in Early Stage Nasopharyngeal Carcinoma Treated with IMRT: A Paired Cohort Study. Medicine. 2015; 94:e1457.

23. Wee CW, Keam B, Heo DS, Sung MW, Won TB, Wu HG. Locoregionally advanced nasopharyngeal carcinoma treated with intensity-modulated radiotherapy plus concurrent weekly cisplatin with or without neoadjuvant chemotherapy. Radiat Oncol J. 2015; 33:98-108.

24. Cao CN, Luo JW, Gao L, Yi JL, Huang XD, Wang K, Zhang SP, Qu Y, Li SY, Xiao JP, Zhang Z, Xu GZ. Concurrent chemotherapy for T4 classification nasopharyngeal carcinoma in the era of intensity-modulated radiotherapy. PLoS ONE. 2015; 10:e0119101.

25. Marta GN, Silva V, de Andrade Carvalho H, de Arruda FF, Hanna SA, Gadia R, da Silva JL, Correa SF, Vita Abreu $\mathrm{CE}$, Riera R. Intensity-modulated radiation therapy for head and neck cancer: systematic review and meta-analysis. Radiotherapy and oncology. 2014; 110:9-15.

26. Chen QY, Wen YF, Guo L, Liu H, Huang PY, Mo HY, Li NW, Xiang YQ, Luo DH, Qiu F, Sun R, Deng MQ, Chen $\mathrm{MY}$, et al. Concurrent chemoradiotherapy vs radiotherapy alone in stage II nasopharyngeal carcinoma: phase III randomized trial. J Natl Cancer Inst. 2011; 103:1761-1770.

27. Xu T, Hu C, Wang X, Shen C. Role of chemoradiotherapy in intermediate prognosis nasopharyngeal carcinoma. Oral oncology. 2011; 47:408-413.

28. Cooper JS. Concurrent chemotherapy and radiation therapy for advanced stage carcinoma of the nasopharynx. International journal of radiation oncology, biology, physics. 2000; 48:1277-1279.

29. Guan Y, Liu S, Wang HY, Guo Y, Xiao WW, Chen CY, Zhao C, Lu TX, Han F. Long-term outcomes of a phase II randomized controlled trial comparing intensity-modulated radiotherapy with or without weekly cisplatin for the treatment of locally recurrent nasopharyngeal carcinoma. Chin J Cancer. 2016; 35:20.

30. Zhang LN, Gao YH, Lan XW, Tang J, Ouyang PY, Xie FY. Effect of taxanes-based induction chemotherapy in 
locoregionally advanced nasopharyngeal carcinoma: A large scale propensity-matched study. Oral oncology. 2015; 51:950-956.

31. Xu T, Shen C, Zhu G, Hu C. Omission of chemotherapy in early stage nasopharyngeal carcinoma treated with IMRT a paired cohort study. Medicine (United States). 2015; 94:e1457.

32. Wee CW, Keam B, Heo DS, Sung MW, Won TB, Wu HG. Locoregionally advanced nasopharyngeal carcinoma treated with intensity-modulated radiotherapy plus concurrent weekly cisplatin with or without neoadjuvant chemotherapy. Radiation Oncology Journal. 2015; 33:98108.

33. Tan T, Lim WT, Fong KW, Cheah SL, Soong YL, Ang MK, Ng QS, Tan D, Ong WS, Tan SH, Yip C, Quah D, Soo KC, et al. Concurrent chemo-radiation with or without induction gemcitabine, carboplatin, and paclitaxel: A randomized, phase $2 / 3$ trial in locally advanced nasopharyngeal carcinoma. International Journal of Radiation Oncology Biology Physics. 2015; 91:952-960.

34. Kong F, Cai B, Lin S, Zhang J, Wang Y, Fu Q. Assessment of radiotherapy combined with adjuvant chemotherapy in the treatment of patients with advanced nasopharyngeal carcinoma: A prospective study. Journal of BUON. 2015; 20:206-211.

35. Huang PY, Zeng Q, Cao KJ, Guo X, Guo L, Mo HY, Wu PH, Qian CN, Mai HQ, Hong MH. Ten-year outcomes of a randomised trial for locoregionally advanced nasopharyngeal carcinoma: A single-institution experience from an endemic area. European Journal of Cancer. 2015; 51:1760-1770.

36. Zeng L, Tian YM, Huang Y, Sun XM, Wang FH, Deng XW, Han F, Lu TX. Retrospective analysis of 234 nasopharyngeal carcinoma patients with distant metastasis at initial diagnosis: Therapeutic approaches and prognostic factors. PLoS ONE. 2014; 9.

37. Yi J, Huang X, Gao L, Luo J, Zhang S, Wang K, Qu Y, Xiao J, Xu G. Intensity-modulated radiotherapy with simultaneous integrated boost for locoregionally advanced nasopharyngeal carcinoma. Radiation Oncology. 2014; 9.

38. Wu RR, Xiao ZY, Wang C, Liu HF, Zhong H, Li F. Phase II clinical trial of h-R3 combined with radiotherapy in locally advanced nasopharyngeal carcinoma. Journal of BUON. 2014; 19:930-936.

39. Wen B, Yang Z, Yan J, Zheng W. Clinical observation on the sensitization effects of Docetaxel on the radiotherapy of nasopharyngeal carcinoma. Anti-Tumor Pharmacy. 2014; 4:135-138.

40. Wang W, Feng M, Fan Z, Li J, Lang J. Clinical outcomes and prognostic factors of 695 nasopharyngeal carcinoma patients treated with intensity-modulated radiotherapy. Biomed Res Int. 2014; 2014:814948.

41. Wu X, Huang PY, Peng PJ, Lu LX, Han F, Wu SX, Hou X, Zhao HY, Huang Y, Fang WF, Zhao YY, Xue C, Hu ZH, et al. Long-term follow-up of a phase III study comparing radiotherapy with or without weekly oxaliplatin for locoregionally advanced nasopharyngeal carcinoma. Annals of Oncology. 2013; 24:2131-2136.

42. Huang S, Deng G, Huang G, Li Y, Meng Y, Chen J. Efficacy of induction chemotherapy combined with concurrent chemoradiotherapy for advanced nasopharyngeal carcinoma. Chinese Journal of Clinical Oncology. 2012; 39:788-791.

43. Fountzilas G, Ciuleanu E, Bobos M, Kalogera-fountzila A, Eleftheraki AG, Karayannopoulou G, Zaramboukas T, Nikolaou A, Markou K, Resiga L, Dionysopoulos D, Samantas E, Athanassiou H, et al. Induction chemotherapy followed by concomitant radiotherapy and weekly cisplatin versus the same concomitant chemoradiotherapy in patients with nasopharyngeal carcinoma: A randomized phase II study conducted by the Hellenic Cooperative Oncology Group (HeCOG) with biomarker evaluation. Annals of Oncology. 2012; 23:427-435.

44. Chen L, Hu CS, Chen XZ, Hu GQ, Cheng ZB, Sun Y, Li WX, Chen YY, Xie FY, Liang SB, Chen Y, Xu TT, Li B, et al. Concurrent chemoradiotherapy plus adjuvant chemotherapy versus concurrent chemoradiotherapy alone in patients with locoregionally advanced nasopharyngeal carcinoma: A phase 3 multicentre randomised controlled trial. The Lancet Oncology. 2012; 13:163-171.

45. Ruste SA, Dizon DS, Ramirez F, Sagpao C, Tiangco B, Fragante E. Induction chemotherapy followed by concurrent chemoradiotherapy vs concurrent chemoradiotherapy followed by chemotherapy in the treatment of patients with advanced nasopharyngeal carcinoma. Phillippine Journal of Internal Medicine. 2011; 49:1-7.

46. Lee AWM, Tung SY, Ngan RKC, Chappell R, Chua DTT, Lu TX, Siu L, Tan T, Chan LK, Ng WT, Leung TW, Fu $\mathrm{YT}, \mathrm{Au} \mathrm{GKH}$, et al. Factors contributing to the efficacy of concurrent-adjuvant chemotherapy for locoregionally advanced nasopharyngeal carcinoma: Combined analyses of NPC-9901 and NPC-9902 Trials. European Journal of Cancer. 2011; 47:656-666.

47. Ding ZL. Clinical analysis of adverse drug reactions (adrs) associated with radiation and chemotherapy combined adjuvant chemotherapy in local advanced nasopharyngeal carcinoma. Clinical Medicine. 2011; 31:82-83.

48. Chen QY, Wen YF, Guo L, Liu H, Huang PY, Mo HY, Li NW, Xiang YQ, Luo DH, Qiu F, Sun R, Deng MQ, Chen $\mathrm{MY}$, et al. Concurrent chemoradiotherapy vs radiotherapy alone in stage ii nasopharyngeal carcinoma: Phase iii randomized trial. Journal of the National Cancer Institute. 2011; 103:1761-1770.

49. Lee AW, Tung SY, Chua DT, Ngan RK, Chappell R, Tung R, Siu L, Ng WT, Sze WK, Au GK, Law SC, O’Sullivan $\mathrm{B}$, Yau TK, et al. Randomized trial of radiotherapy plus concurrent-adjuvant chemotherapy vs radiotherapy alone for regionally advanced nasopharyngeal carcinoma. J Natl Cancer Inst. 2010; 102:1188-1198. 
50. Hui EP, Ma BB, Leung SF, King AD, Mo F, Kam MK, Yu BK, Chiu SK, Kwan WH, Ho R, Chan I, Ahuja AT, Zee $\mathrm{BC}$, et al. Randomized phase II trial of concurrent cisplatinradiotherapy with or without neoadjuvant docetaxel and cisplatin in advanced nasopharyngeal carcinoma. Journal of Clinical Oncology. 2009; 27:242-249.

51. Ge FH, Yang YG, Cai J, Wan ZL, Xie GD. The Clinical Observation of Sodium Glycididazole (CMNa) on Enhancement of Radiation Sensitivity for Nasopharyngeal Cancer. Journal of Basic and Clinical Oncology. 2009; 22:134-136

52. Chen Y, Liu MZ, Liang SB, Zong JF, Mao YP, Tang LL, Guo Y, Lin AH, Zeng XF, Ma J. Preliminary Results of a Prospective Randomized Trial Comparing Concurrent Chemoradiotherapy Plus Adjuvant Chemotherapy With Radiotherapy Alone in Patients With Locoregionally Advanced Nasopharyngeal Carcinoma in Endemic Regions of China. International Journal of Radiation Oncology Biology Physics. 2008; 71:1356-1364.

53. Lai XJ, Zheng X, Liu G. Radiosensitizing Effect of Metronidazole Amino Acidum Natrium (CMNa) on Nasopharyngeal. Journal of Oncology. 2007; 63:189-191.

54. Wu S, Yang JL, Li ZL, Xu K, Wang JC, Lang JY, Wen H. Radiosensitivity on Nasopharyngeal Carcinoma by CMNa. Cancer Res Prey Treat. 2006; 33:200-201.

55. Liu MZ, He LR, Lu TX, Chen YY, Hu YH, Cui NJ, Xu GZ, Gao L, Xiao GL, Zhang SW, Cai Y, Li DM, Chen LH, et al. Effect of hypoxic radiosensitizer sodium glycididazole on long-term result of radiotherapy for nasopharyngeal carcinoma. [Article in Chinese]Chinese journal of oncology. 2006; 28:932-937.

56. Zhang L, Zhao C, Peng PJ, Lu LX, Huang PY, Han F, Wu SX. Phase III study comparing standard radiotherapy with or without weekly oxaliplatin in treatment of locoregionally advanced nasopharyngeal carcinoma: Preliminary results. Journal of Clinical Oncology. 2005; 23:8461-8468.

57. Chan ATC, Leung SF, Ngan RKC, Teo PML, Lau WH, Kwan WH, Hui EP, Yiu HY, Yeo W, Cheung FY, Yu KH, Chiu KW, Chan DT, et al. Overall survival after concurrent cisplatin-radiotherapy compared with radiotherapy alone in locoregionally advanced nasopharyngeal carcinoma. Journal of the National Cancer Institute. 2005; 97:536-539.

58. Lin JC, Jan JS, Hsu CY, Liang WM, Jiang RS, Wang WY. Phase III study of concurrent chemoradiotherapy versus radiotherapy alone for advanced nasopharyngeal carcinoma: Positive effect on overall and progression-free survival. Journal of Clinical Oncology. 2003; 21:631-637.

59. Chi KH, Chang YC, Guo WY, Leung MJ, Shiau CY, Chen SY, Wang LW, Lai YL, Hsu MM, Lian SL, Chang CH, Liu TW, Chin YH, et al. A phase III study of adjuvant chemotherapy in advanced nasopharyngeal carcinoma patients. International Journal of Radiation Oncology Biology Physics. 2002; 52:1238-1244.
60. Ma J, Mai HQ, Hong MH, Min HQ, Mao ZD, Cui NJ, Lu TX, Mo HY. Results of a prospective randomized trial comparing neoadjuvant chemotherapy plus radiotherapy with radiotherapy alone in patients with locoregionally advanced nasopharyngeal carcinoma. Journal of Clinical Oncology. 2001; 19:1350-1357.

61. Chua DT, Sham JS, Choy D, Lorvidhaya V, Sumitsawan Y, Thongprasert S, Vootiprux V, Cheirsilpa A, Azhar T, Reksodiputro AH. Preliminary report of the Asian-Oceanian Clinical Oncology Association randomized trial comparing cisplatin and epirubicin followed by radiotherapy versus radiotherapy alone in the treatment of patients with locoregionally advanced nasopharyngeal carcinoma. AsianOceanian Clinical Oncology Association Nasopharynx Cancer Study Group. Cancer. 1998; 83:2270-2283.

62. Al-Sarraf M, LeBlanc M, Giri PG, Fu KK, Cooper J, Vuong T, Forastiere AA, Adams G, Sakr WA, Schuller DE, Ensley JF. Chemoradiotherapy versus radiotherapy in patients with advanced nasopharyngeal cancer: phase III randomized Intergroup study 0099. Journal of clinical oncology. 1998; 16:1310-1317.

63. Cvitkovic E, Eschwege F, Rahal M, Dosen, Mersic Z, Krajina Z, Armand JP, Bouhris J, Tubiana-Mathieu M, Fountzilas G, Kosmidis PA, Prasad U, Ganesan S, et al. Preliminary results of a randomized trial comparing neoadjuvant chemotherapy (cisplatin, epirubicin, bleomycin) plus radiotherapy vs. Radiotherapy alone in stage IV $(\leq \mathrm{N} 2, \mathrm{M} 0)$ undifferentiated nasopharyngeal carcinoma: A positive effect on progression-free survival. International Journal of Radiation Oncology Biology Physics. 1996; 35:463-469.

64. Chan AT, Teo PM, Leung TW, Leung SF, Lee WY, Yeo $\mathrm{W}$, Choi PH, Johnson PJ. A prospective randomized study of chemotherapy adjunctive to definitive radiotherapy in advanced nasopharyngeal carcinoma. International journal of radiation oncology, biology, physics. 1995; 33:569-577.

65. Rossi A, Molinari R, Boracchi P, Del Vecchio M, Marubini E, Nava M, Morandi L, Zucali R, Pilotti S, Grandi C, Ambrosini G, Cellini N, Chiavacci A, et al. Adjuvant chemotherapy with vincristine, cyclophosphamide, and doxorubicin after radiotherapy in local-regional nasopharyngeal cancer: Results of a 4-year multicenter randomized study. Journal of Clinical Oncology. 1988; 6:1401-1410. 